\title{
DISTAL ESOPHAGEAL PERFORATION CAUSED BY TUBERCULOSIS
}

Brian C. Grubbs, MD, ${ }^{a}$ Douglas R. Baldwin, MD, ${ }^{a}$ Stephan W. Trenkner, MD, ${ }^{b}$ Robert P. McCabe, Jr, MD, ${ }^{\mathrm{c}}$ and Michael A. Maddaus, MD, ${ }^{\mathrm{a}}$ Minneapolis, Minn

Tuberculous involvement of the esophagus is rare. Typically, esophageal involvement is caused by contiguous extension of mediastinal disease and is rarely a primary infection. Regardless of the pathogenesis, the infected esophagus can stricture or perforate. Herein we report a recent case of esophageal perforation caused by tuberculosis, emphasizing the nonoperative management of such lesions.

Clinical summary. A 39-year-old male African immigrant presented to a primary care clinic with burning epigastric pain exacerbated by food intake. Serologic tests were positive for Helicobacter pylori, and acid-suppressive and antibiotic therapy was started. He returned 3 months later with a 12-pound (5.3-kg) weight loss and recent onset of severe epigastric and retrosternal pain and fever. Physical examination revealed a low-grade fever and oral candidiasis. The white blood cell count was $4.3 \times 10^{9} / \mathrm{L}$. Examination with an esophagoscope showed confluent distal esophagitis, white nodules, and a perforation a few centimeters above the esophagogastric junction (Fig 1).

Chest computed tomography revealed a $3.5 \times 3.5-\mathrm{cm}$ softtissue mass with a central area of low attenuation contiguous with the esophagus at the level of the esophagogastric junction. Esophagography showed a distal esophageal perforation, with contrast material filling an adjacent cavity and free drainage of the contrast material back into the esophagus (Fig 2). On hospital day 2, acid-fast stains and polymerase chain reaction for Mycobacterium tuberculosis complex DNA from esophageal biopsy specimens were positive for acid-fast bacteria. Triple-drug antituberculosis therapy was started. Additional testing was positive for human immunodeficiency virus antibody. The patient remained hemodynamically stable through the remainder of his hospital course. A chest computed tomogram 19 days after admission demonstrated resolution of inflammation around the distal perforation, with a decrease in the size of the cavity. A contrast esophagogram at 3 weeks showed a small residual collection of contrast material but a significant decrease in the cavity size.

Discussion. The Division of Tuberculosis Elimination of the Centers for Disease Control and Prevention reported slightly more than 17,000 new documented cases of tuberculosis in the United States in 1999 (www.cdc.gov/nchstp/tb/).

From the Division of Cardiovascular and Thoracic Surgery, Department of Surgery, University of Minnesota, Minneapolis; Department of Radiology, ${ }^{\mathrm{b}}$ University of Minnesota, Minneapolis; and Minnesota Gastroenterology, ${ }^{\mathrm{c}}$ PA, Minneapolis, Minn.

J Thorac Cardiovasc Surg 2001;121:1003-4

Copyright (C) 2001 by The American Association for Thoracic Surgery

0022-5223/2001 $\$ 35.00+0 \quad \mathbf{1 2 / 5 4 / 1 1 1 1 9 6}$

doi: $10.1067 / \mathrm{mtc} .2001 .111196$

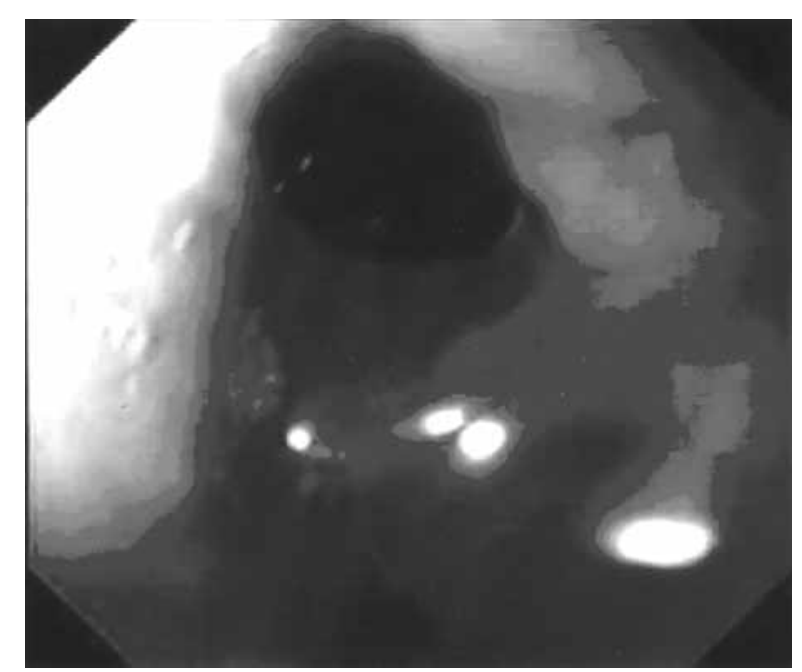

Fig 1. Endoscopic view, with distal esophageal perforation at left.

Although the US incidence has fluctuated over the past decade (peaking at 26,000 in 1992), worldwide estimates predict a bleak future. The global burden of tuberculosis remains enormous, with an estimated 2 billion infected persons and 8 million new cases added each year. Thoracic surgeons can expect to encounter increasing numbers of patients emigrating from regions of the world with endemic tuberculosis.

Tuberculosis has been posited to involve the esophagus, either as a primary infection or as a secondary manifestation of reactivation disease. Primary infection of the esophagus without demonstrable evidence of concurrent pulmonary or focal thoracic lesions has been reported in rare instances; some authorities doubt its existence. ${ }^{1}$ The rapid clearance of infected sputum by means of coordinated peristalsis, combined with upright posture and an intact lower esophageal sphincter, limit the exposure of the esophagus to the organism.

Most esophageal tuberculosis develops because of reactivation disease and results from the direct extension of contiguous caseous mediastinal lymph nodes and pulmonary complexes. The middle third of the esophagus is the segment most frequently involved. Other manifestations of secondary esophageal tuberculosis include ulceration, stricture, and fistula tract formation between the esophagus and nearby mediastinal structures. ${ }^{3}$ Scarring and retraction associated with mediastinal tuberculosis can cause traction diverticula of the midesophagus.

To our knowledge, this case represents only the fifth case of perforation of the esophagus caused by tuberculosis and the first case of distal perforation. ${ }^{4-7}$ 


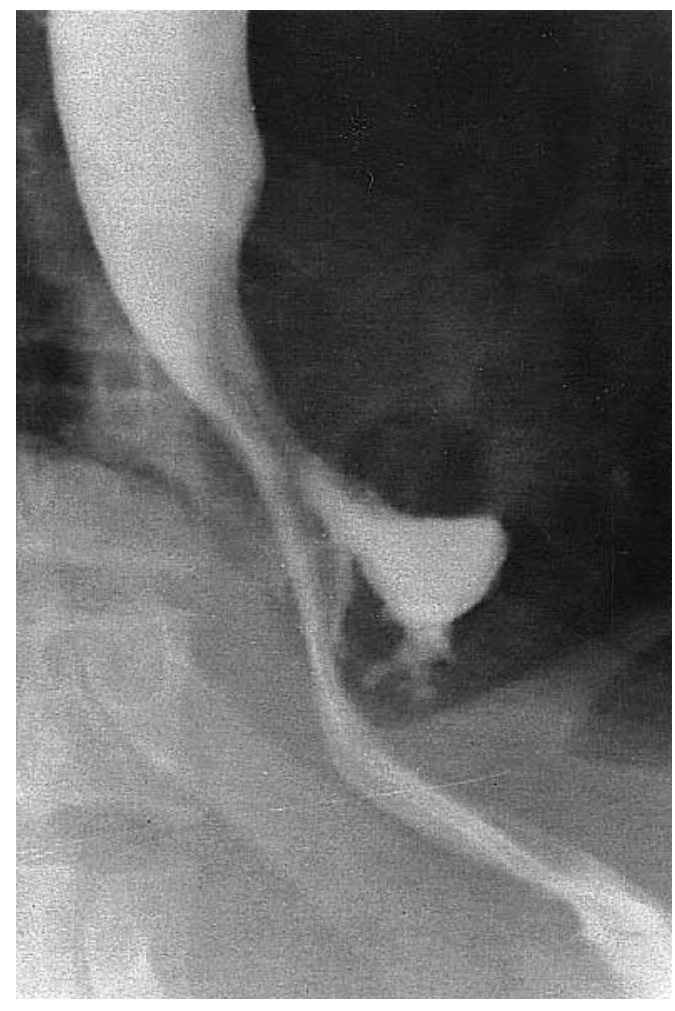

Fig 2. Contrast esophagogram showing distal perforation and contrast extravasation into mediastinal cavity.

Newman and associates ${ }^{2}$ reviewed the 27 cases of esophageal tuberculosis in the literature through 1990 and found that more than $75 \%$ of patients had a primary complaint of chronic dysphagia. ${ }^{2}$ Other symptoms included weight loss, hematemesis, and productive cough suggestive of tracheoesophageal fistula formation. Symptoms associated with perforation were not reported in that review, but in our patient the suddenly increased retrosternal pain, accompanied by fever, suggested esophageal perforation.

Although surgical intervention is rarely required for esophageal tuberculosis, the high mortality associated with esophageal perforation mandates the consideration of operative management. The preferred surgical option for a nonmalignant perforation would include primary mucosa repair, debridement of devitalized tissue, and drainage ${ }^{8}$ Our decision to treat this patient nonoperatively reflected the infectious cause, the absence of sepsis, the free drainage of contrast material back into the esophagus at esophagography, and the lack of extension of the process into either pleural cavity.

In summary, esophageal perforation caused by tuberculosis is rare. It results from the gradual encroachment of mediastinal disease during reactivation, rather than as a primary infection. The possibility of surgery depends on the patient's clinical condition; however, even in the setting of perforation, esophageal tuberculosis can be treated nonoperatively.

Received for publication Aug 8, 2000; accepted for publication Aug 31, 2000.

Address for reprints: Michael A. Maddaus, MD, University of Minnesota, Department of Surgery, MMC 207 Mayo, 420 Delaware St, SE, Minneapolis, MN 55455 (E-mail: madda001@tc.umn.edu).

\section{REFERENCES}

1. Marshall JB. Tuberculosis of the gastrointestinal tract and peritoneum. Am J Gastroenterol 1993;88:989-99.

2. Newman RM, Fleshner PR, Lajam FE, Kim U. Esophageal tuberculosis: a rare presentation with hematemesis. Am J Gastroenterol 1991;86:751-5.

3. Dye C, Scheele S, Dolin P, Pathania V, Raviglione MC. Global burden of tuberculosis: estimated incidence, prevalence, and mortality by country. JAMA 1999;282:677-86.

4. Adkins MS, Raccuia JS, Acinapura AJ. Esophageal perforation in a patient with acquired immunodeficiency syndrome. Ann Thorac Surg 1990;50:299-300.

5. Schroeder J, Siemann M, Vogel I, Thybusch A, Kremer B. Sepsis syndrome induced by tuberculous perforation of the esophagus. Infection 1996;62:162-3.

6. Ghandour Z, Al Karawi MA, Mohamed AE. Spontaneous esophageal perforation: unusual presentation of tuberculosis. Endoscopy 1997;29:143-4.

7. Williford ME, Thompson WM, Hamilton JD, Postlethwait RW. Esophageal tuberculosis: findings on barium swallow and computed tomography. Gastrointest Radiol 1983;8:119-22.

8. Whyte RI, Iannettoni MD, Orringer MB. Intrathoracic esophageal perforation: the merit of primary repair. J Thorac Cardiovasc Surg 1995;109:140-6. 